\title{
Critical Pedagogy as an Approach to Multimodal Video Projects in Korean English Education Classrooms
}

\author{
Pederson, Rod \\ (Incheon National University)
}

Pederson, Rod. (2018). Critical pedagogy as an approach to multimodal video projects in Korean English education classrooms. STEM Journal, 19(2), 195-219.

This paper reports on a qualitative study investigating the utility of multimodal approaches to pedagogy at a Department of English Education at a Korean University in a Multimedia English Education course. The course was a workshop course where students formed groups to construct multimodal video representations and digital storytelling videos using student chosen topics on important Korean and international social issues. Applying critical pedagogy (CP) as an approach to instructor-student interactions (Kincheloe, 2004), the researcher regularly joined student group discussions to participate in each group's practice of inquiry into their topics and the construction of their multimodal video representations. Field notes were recorded including observations of student working behavior and group discussions in order to determine the types of subjects students favored, how multimodal video projects affected student language learning, how these projects affected student engagement, and how they affected students' development of critical thinking skills. Results of the study found that the $\mathrm{CP}$ approach applied reduced student language fear and cultural knowledge, facilitated student engagement, and the development of critical thinking skills. The results of this study suggest the utility of using CP approaches to multimodal pedagogy in secondary and tertiary English Education classrooms.

\section{INTRODUCTION}

Over the past 20 years literature in applied linguistics has increasingly acknowledged, developed, and adopted multimodal and multiliteracies approaches to English language teaching (ELT). Theories of multimodality are based on the understanding that human meaning-making is expressed not only through linguistic relations but also in other forms (modalities) that carry meaning such as visual and audio texts and body language (Jewitt, 2008; Kress, 2010), whereas multiliteracies is a pedagogical application to develop the 
requisite understandings and skills necessary to decode multimodal texts (Goldman, 2007; Kress, 2010). The theoretical understanding that much of the meanings humans make is extra-linguistic in nature has been appropriated into the theories and practices of computer assisted language learning (CALL), multimedia assisted language learning (MALL) (Dudeney, 2007; Lamy \& Hampel, 2007), and the use of film in ELT (Chapple \& Curtis, 2000; Eken, 2003), along with a variety of other pedagogical applications including critical pedagogy (CP) that may be subsumed under a general definition of multimodal or multiliteracies approaches to ELT (Freyn, 2017; Guichon \& McLornan, 2008; Pennycook, 2001; Royce, 2002). The key aspect of this theoretical and pedagogical movement in ELT and the other social sciences is the understanding that meaning may not be restricted to a single modality, such as language, but is inherently multimodal in nature (Gee, 2010; Jewitt, 2008; Kress, 2010). In many of the social sciences such as critical pedagogy, cultural studies, and sociology, multimodal theory is often referred to as theories of representation (Foucault, 1984; Giroux, 1997; Hall, 1997). With the advent of CALL in the early ages of computers and information technology, and MALL as its most current form, multimodal and multiliteracies approaches to ELT have become increasing important in ELT literature and pedagogy (Freyn, 2017; Guichon \& McLornan, 2008; Royce, 2002). In addition, these diverse theoretical understandings of language and meaning have also included an increase in the appropriation of CP into applied linguistics literature and practice (Morgan, 2006; Pennycook, 2001).

His qualitative study attempts to better understand how $\mathrm{CP}$ approaches to multimodal student video representation projects facilitate ELT student learning and classroom environments. In an English Education department at a mid-size university in the Seoul/Incheon metropolitan area, this study collected data from the course Multimedia English Education from the fall semester of 2016. This course was a project-based course where student groups were assigned to create three video representation projects over the semester on self-selected topics. Through the use of film clips, video news stories, Korean public school English textbooks, and Korean television commercials, students were sensitized to an awareness of how various readings of multimodal representations in multimedia artifacts were not only possible, but inevitable according to the social positioning and education of the individual viewer. This knowledge regarding the nature of representation was intended to facilitate students' understanding of multimodality, creativity, and critical thinking skills in the construction of their group video projects. This qualitative study consisted of three techniques of data gathering including focus group interviews, classroom observations, and student projects in order to better understand how students responded to a $\mathrm{CP}$ approach to the creation of student group multimodal video representations. 


\section{LITERATURE REVIEW}

\section{Multimodality and Multiliteracies}

Although representation is a much-used theoretical foundation for the analysis of meaning in the social sciences (Hall, 1997), the terms multimodality and multiliteracies have come to be the common theoretical terms used in education and ELT to denote the existence of meaning beyond purely linguistic textuality (Freyn, 2017; Guichon \& McLornan, 2008; Royce, 2002). According to Hung and Yuen (2014), these theoretical terms were established by The New London Group to define how different 'channels' of meaning coexisted with the purely linguistic conceptions of textuality. However, it is important to understand that while these two terms are related, and may often be conflated in meaning, they are actually two different understandings of representational theory. The key aspect of the pedagogical utility of representation is the understanding that as meaning is continually in flux; its meaning is never fixed into one specific representation (Hall, 1997). Thus, any specific representation has dominant and subaltern readings which allow for a contestation of meaning within a society which, thereby, opens possibilities for positive social change (Giroux, 1997). This representational view of meaning allows educators to use film and other forms of media to better contextualize language and literature in ways that reveal more detailed understandings of the socio-cultural milieu that construct human meaning and creates a space in the classroom where knowledge may be questioned and transformed (Beach \& Myers, 2001). Thus, the term multimodality necessarily defines meaning as an interconnection among disparate modes, or carriers of meaning, which must all be 'decoded' in order to understand the entire meaning of a specific artifact or utterance (Freyn, 2017; Hall, 1997; Royce, 2002).

Jewitt (2008) and Gee (2010) define multimodality as existing phenomenon such as audio, visual, action, gesture, body posture, and language, etc., whereas multiliteracies is the development of the necessary competencies to decode the meanings within multimodality. Kress (2010) describes the development of this theoretical movement as resulting from the transition of an age of a medium of print textuality to the current electronic forms of textuality in the information age. These understandings of representation and its power on meaning making have also given rise to what has come to be known as critical media literacy CML (Beach, 2007), which furthers the definition of multiliteracies as a student who is not capable of decoding the various representations in current multimodal media texts is viewed as being illiterate in terms of understanding meaning in an IT world (Kress \& Van Leeuwen, 2006). Thus, scholars such as Goldman (2007), Jewitt (2008), and Kress (2010) not only maintain that the development of multiliteracies is necessary in education, it is also necessary for students to engage in 
inquiry and create their own multimodal representations of literature, films, and current issues in society in order to be able to be fully prepared to engage as a citizen in a modern democratic society. Thus, these understandings of representation and textuality have been appropriated into pedagogical approaches such as CP (Giroux, 1997; Kincheloe, 2004), inquiry education (Beach \& Myers, 2001; Crafton \& Kaiser, 2011), and CML (Kellner \& Share, 2007; Meyers \& Beach, 2004). These understandings of the importance and use of multiliteracies approaches to education have been appropriated by ELT scholars and used to great effect, both within the MALL community and general ELT practitioners (Freyn, 2017; Guichon \& McLornan, 2008; Royce, 2002). Thus, multiliteracies approaches to ELT may be seen to not only facilitate the common linguistic approaches to second language learning, but also serve the function of contextualizing culture that is at the heart of communicative language teaching (CLT) (Savignon, 2002).

Much of the pedagogical use of film in ELT stems from the appropriation of multiliteracy approaches to English education (Beach \& Myers, 2001; Kress, 2010). The use of film for pedagogical purposes in ELT gained its major impetus from Hymes' (1967) seminal work Why the Linguist needs the Sociologist, which ultimately lead the development of CLT (Savignon, 2002). Hymes' (1967) essential argument was that social practices may not be separated from linguistic utterances in decoding meaning. Thus, in time CLT became the dominant approach to ELT in the professional literature and theoretically viewed language and culture as a dialectic relationship of mutually coconstructive aspects of meaning (Savignon, 2002). Kramsch's (1993) assertion that ELT was essentially teaching language through culture most clearly represents this discursive view of language learning.

\section{Critical Pedagogy}

The genesis of critical pedagogy is generally attributed to the critical literacy (CL) of Paulo Freire (1970) with the purpose of creating a form of pedagogy that has the ability to demystify relations of power in society for the purposes of social justice and social agency (Giroux, 1997). As the terms CL and CP are often elided in the professional literature, for the purposes of clarity this paper will only use the term CP. Currently, CP has become an umbrella term that subsumes many theoretical and pedagogical perspectives within it bounds such as theories of multimodality and multiliteracies (Meyers \& Beach, 2007; Morgan, 2006) representation (Hall, 1997), inquiry education (Beach \& Meyers, 2001), communities of practice (CoP) (Lave \& Wenger, 1991), critical media literacy (Beach, 2007), feminist theory (Bordo, 2003), and other theories and practices too numerous to mention within the context of this study. Generally, the practice of $\mathrm{CP}$ entails creating a space within the classroom where dialogic, situated, forms of pedagogy allow students to 
question and investigate the multimodal meanings within the content of the curriculum in order to create new forms of language, culture, and meaning (Hall, 1997). In doing so, the instructor serves both as a source of knowledge and as a facilitator to the practices of inquiry within the classroom, which is in keeping with $\mathrm{CoP}$ approaches to pedagogy (Barton \& Hamilton, 1999). In doing so, the instructor not only hopes to facilitate student development of critical thinking, but to also better engage students in acquiring, understanding, and applying the forms of knowledge they are exposed to in ways that foster individual social agency and have a transformative potential within society (Giroux, 1997; Kincheloe, 2004).

According to Barbules and Berk (1999) the key aspect of CP is understanding the question of 'Who benefits?' in terms of understanding any form of knowledge, or as Luke (2011) puts it:

What is 'truth'? How is it presented and represented, by whom, and in whose interests? Who should have access to which images and words, texts and discourses? For what purposes? (p.2)

Essentially this entails a cycle of inquiry that includes an examination of content knowledge through the processes of situating the knowledge into social contexts (situated learning) (Lave \& Wenger, 1991), classroom discussion between students and instructors (dialogism) (Freire, 1970; Vygotsky, 1978), construction of multimodal student representation of the knowledge, and the publishing of this knowledge (Freire, 1998). According to Kincheloe (2004) this form of pedagogy facilitates student engagement and the demystification of the discursive relationship between knowledge, social practices, and relations of power. As such, it opens the possibilities for positive social change. Within applied linguistics, CP has been applied to many contexts such as Canagarajah's (1999) theorization of linguistic imperialism as well as Norton's (2000) inquiry into the construction of second language identity. Thus, the use of CP in ELT allows for students to not only contextualize the language and culture that they are learning, but also to better understand how the relations of culture and power affect themselves and their societies. Finally, it is important to understand that while the purposes of $\mathrm{CP}$ are student conscientization (Freire, 1970), or becoming critically aware in mind, and the facilitation of social justice and agency, this does not mean that each class is necessarily devoted to these aims, or that they will be realized. Often, the results are simply a better understanding of how knowledge may be applied in society (Sung \& Pederson, 2012). 


\section{Pedagogical Use of Film in ELT}

While the pedagogical use of film in ELT has been dominated by linguistic purposes since its inception through pedagogical applications to improve vocabulary acquisition (Warschauer \& Meskill, 2000), conversation skills and speech proficiency (Bahrani \& Tam, 2011), grammatical accuracy (Sommer, 2001), and pronunciation (Curtis, 2007), much research has also been done on the use of films for the generation of discussion topics (Kaiser, 2011), increasing student motivation (Chapple \& Curtis, 2000; Liversidge, 2000), supplying authentic linguistic and cultural contexts (Butler-Pascoe \& Wiburg, 2003), and the development of critical thinking skills (Chapple \& Curtis, 2000). It is important to note that the non-linguistic aspects of these various approaches were adopted from multimodal research done in the field of English education (Freyn, 2017; Guichon \& McLornan, 2008; Royce, 2002). Thus, the use of films in ELT practice serves both the linguistic and cultural necessities of communicative or social-constructivist practices. In addition, the use of films in the ELT classroom may take many different forms such as the use of full-length feature films (King, 2002), film clips (Sommer, 2001), YouTube videos (Terantino, 2011), and various internet multimedia forms (Butler-Pascoe \& Wiburg, 2003), depending on the specific goals of the instructor. Moreover, there has been an increasing movement towards the pedagogical value of student constructed video representations in English education (Beach, 2007; Beach \& Myers, 2001) and ELT (Wang, 2015). Such group constructed video representations not only foster the linguistic competencies of the students (Bahrani \& Tam, 2011), they also facilitate student motivation (Liversidge, 2000; Ward \& Lepeintre, 1996), cultural understanding (Hinkel, 1999), and critical thinking skills (Chapple \& Curtis, 2000; Eken, 2003). Thus, the use of film and other multimodal approaches have gained greater acceptance in ELT literature and practice.

\section{METHODS}

\section{Setting}

This study was undertaken in a Department of English Education at a midsize university in the Seoul-Incheon metropolitan area. Data was collected during the fall semester of 2016 in a course entitled Multimedia English Education. The class was taught as a workshop course where students read and discussed the course text Technology and Teaching Language Learners (Butler-Pascoe \& Wiburg, 2003) and were assigned to construct three group video representations over the course of the semester. As the course was project-based, no tests were given, and grading depended on the quality of the 
respective group projects. The course was scheduled for two different class periods on separate days with one class being 50 minutes and the other 110 minutes in length. The 50-minute class focused on lectures and discussions regarding the course text which detailed specific theories of learning through the use of multimedia texts, such as the motivational value of using multimedia texts that were more situated within student experiences and how these theories might be applied to the ELT classroom (Beach \& Myers, 2001; Chapple \& Curtis, 2000). In doing so, these classes were designed to foster the development of creativity and critical thinking as opposed to the memorization of relevant information for the purposes of testing. The class had 14 students who formed three different inquiry groups for the construction of video representations on topics of their choice. Students constructed their multimodal video representations using Movie Maker, with the video representations being between four to eight minutes in length.

The workshop section of the course was conducted during the 110-minute class sessions and consisted of individual groups brainstorming topics and the possible sequencing of components of the videos, the construction of storyboards, constructions of the video representations, and their presentation in class. The instructor/researcher also dedicated the first three periods of the course to introducing students to the discursive nature of meaning and representation in order to help students develop their critical thinking skills and an understanding of the workings of representation and meaning in multimedia texts. Student groups were assigned to use multimodalities to construct one digital storytelling video and two video representations of topics of their choice. In each case, students used digital photos, captured video clips, student scripted videos, written text, and soundtracks that included student voices, music, and a variety of other audio in the construction of their video representations. The use of student constructed digital storytelling videos is a wellrecognized pedagogical approach within both English education and ELT that tells the story of a specific person and is used for the purposes of the development student language proficiency, individual voice, increased motivation, creativity, and critical thinking skills (Miller \& Kim, 2015; Vinogradou, Linville, \& Bickel, 2011). While less widespread, the pedagogical value of student group construction of multimodal video representations of important social issues mirrors that of digital storytelling but also includes the necessary ingredient of student inquiry into the chosen topic and situating it within the students' context (Beach \& Myers, 2001). Thus, the multimodal video representations of social issues required greater discussion, planning, creativity, and critical thinking skills than that of digital storytelling. 


\section{Data Collection}

The qualitative research conducted in this study consisted of gathering data from focus group interviews, classroom observations, and student projects. As the course was workshop-based and focused on student group construction of multimodal video representations, the majority of class time was given over of the autonomous activities of the three student groups. Each group was free to move to other classrooms, computer rooms, or other available spaces to conduct their work in isolation, free from the distractions that exists in ordinary classrooms. As such, the instructor routinely circulated from one group to another observing student groups as well as joining their discussions. In doing so, the instructor was not only able to observe the workings and progress of individual groups, but also to engage in focus group interviews (group discussions) which generated data regarding their attitudes towards the course, their ideas regarding the subjects they were trying to represent through multimodal video representations, and the thinking processes that formed their video constructions. This form of pedagogy was based on a CP approach where the instructor is both a part of the workings of the class as well as a mentor and facilitator to students (Beach \& Myers, 2001; Kincheloe, 2004). In addition, the necessary circulation of the researcher and subsequent observational time allowed the researcher ample time for taking detailed field notes that consisted of student movements and attitudes while engaged in group work, the content of discussions and thinking of the students, and the perceptions of the researcher regarding the overall nature of each group's activities. The researcher also read and reflected upon the field notes taken during class which allowed the researcher to add additional insights regarding class activities to the raw data. Thus, the data gathering techniques of observation, focus group interviews, and field notes followed common research guidelines (Creswell, 2003; Denzin \& Lincoln, 2011).

As this study focused on gaining a better understanding of how students responded to a CP approach in the process of the creation of student group multimodal video representations, the research questions this study will attempt to better explicate are as follows:

1) What types of subjects did students favor and why?

2) How did multimodal video projects affect student language learning?

3) How did the CP approach to creating student group video representation projects affected student engagement?

4) How did this approach affect student development of critical thinking skills? 
It is necessary to state that as the course did not entail any objective language testing, student development of communicative competency was not possible. However, this purely linguistic perspective on language learning obfuscates important socialconstructivist aspects of language learning such as language fear (Ellis, 1994; MacIntyre \& Gardner, 1991), or the affective filter (Krashen, 1982), and the acquisition of the adequate cultural knowledge necessary to attain L2 fluency as is theorized by communicative and other social-constructivist approaches to ELT (Lantolf, 2006; Savignon, 2002).

\section{Data Analysis}

This study employed grounded theory as its method of data analysis for all three individual sets of data. According to Strauss and Corbin (1998) grounded theory entails continual readings of data sets until patterns begin to emerge from the data. These patterns become the major 'codes' that form the results of the study. One of the primary purposes of a grounded theory approach to data analysis is that the researcher needs to approach his research from a position of theoretical neutrality, or naiveté, so that the results (codes) that emerge from the data are more objective than theory-driven data analysis techniques, which is why this form of data analysis is often referred to as a 'blank slate' approach (Denzin \& Lincoln, 2011; Strauss \& Corbin, 1998;). Thus, theory is applied to explicate the codes that emerge from the data. As such, grounded theory is often used to explore and/or describe the social practices in a specific context. This qualitative approach to data gathering allowed the researcher to analyze data from disparate data sets to produce a more holistic examination of what occurred in the class under research. Finally, student names that appear in this research have been anonymized to protect their privacy.

\section{RESULTS}

\section{Culture}

The major codes that emerged from data analysis were culture, student engagement, student selection of topics, and development of critical thinking skills. Within the code of culture, one of the sub-codes that emerged from the data was language fear. While this code was also related to student engagement, it relates more to the code of culture as it is intimately connected to the culture of ELT practices in Korea (Shin, 2010). Specifically, teacher-centered approaches such as the grammar translation method (GTM) and the audio-lingual method (ALM) are shown to produce language fear in students (Ellis, 1994; 
MacIntyre \& Gardner, 1991). The data showed that several students displayed a reluctance to speak in English, particularly when the instructor joined student group discussion. The following excerpt of an early semester group discussion regarding the trend of commercial establishments instituting 'No Kids Zones' is indicative of language fear some of the students labored under.

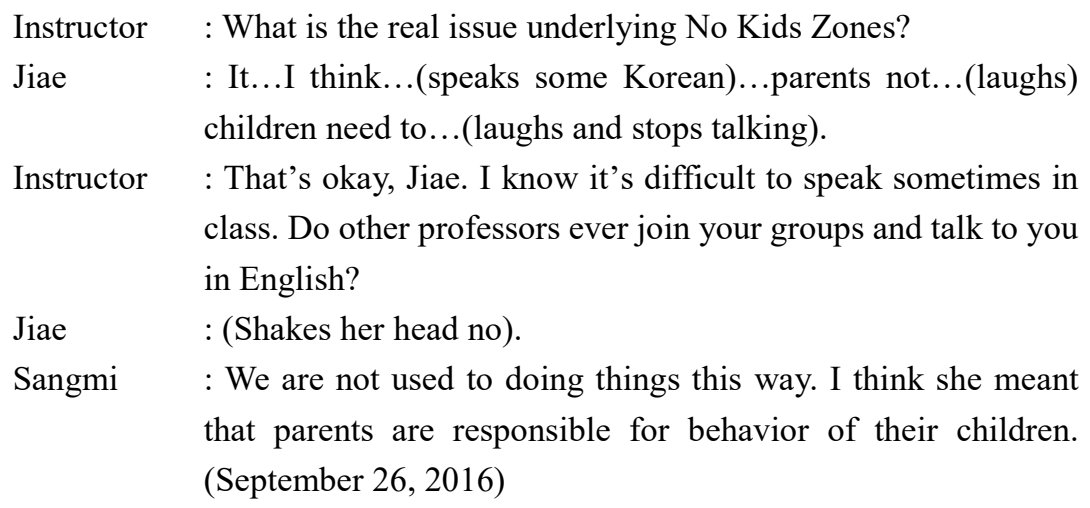

Sangmi : We are not used to doing things this way. I think she meant that parents are responsible for behavior of their children. (September 26, 2016)

Regardless of Jiae's apparent fear of speaking English in a group setting, observational data showed that she nonetheless was actively engaged in the group's work. Similarly, over the semester long instructor engagement in student group discussions, all students displayed a reduction of language fear over time. The following excerpt from a group discussion on gender equality is commensurate with the language behaviors of other students displaying language fear.

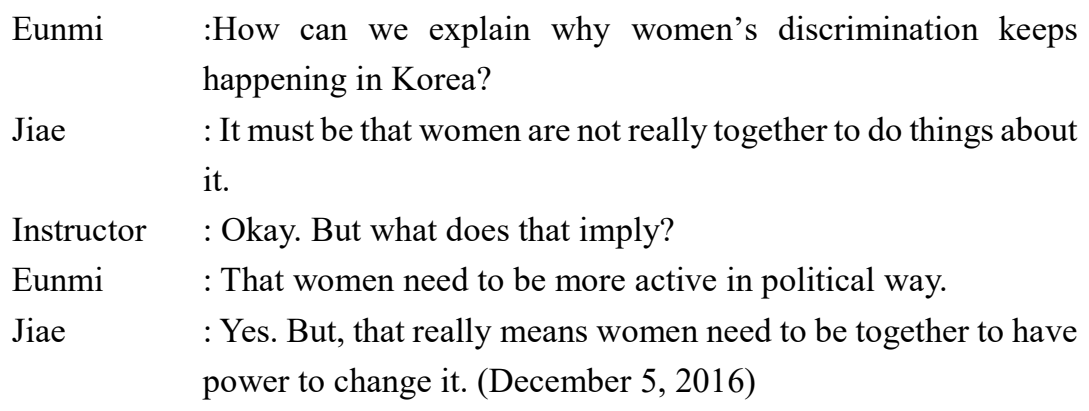

Here, Jiae displays that she not only has the ability to speak comprehensible English, but overcome some of the fear that had been holding her back earlier in the semester. Thus, the data illustrated how a $\mathrm{CP}$ approach encouraged the modification of student language behavior in terms of language fear.

In keeping with the $\mathrm{CP}$ approach of the course, students were encouraged to always 
consider the cultural aspects of the projects they were working on. In addition, students were also encouraged to pay attention to the visual and audio aspects of their work and what meanings they were attempting to represent. Many of the group discussions the instructor was involved in revolved around the meanings of specific representations of digital photos and video clips to be used in students' video representations. While the majority of student topics focused on a social issue within Korean society, two had a broader, international aspect. However, during group discussions the researcher asked questions and made suggestions of how the topic under discussion was represented in other nations, such as within American media. For example, one group of four female students planned to construct a video regarding gender equality and how Korean women were often represented as impossibly pretty, as sexual objects, and almost always depicted in traditional female roles such as cooking and cleaning. In attempting to facilitate critical thinking, the researcher asked questions such as "Is this representation of women unique to Korea, or do other nations have similar representations of women?", and "What effect do these representations have on Korean women and who benefits from this?" (November 14, 2016). These types of questions stirred the discussion and garnered responses from "All supermodels are too pretty and they even Photoshop them anyway" (Nari: November 14, 2016), to "I think it makes Korean women feel bad about themselves so they buy expensive clothes and have plastic surgery" (Eunmi: November 17, 2016). In addition, the researcher was asked how these issues were represented in American media. The results of such discussions caused the students in the group to research how other cultures represented women in media and include their findings in their video representation. In this way, the researcher encouraged all groups to inquire into how their specific subjects were represented internationally and if Western representations had any influence on the issues they were examining in Korean culture. Thus, students gained variegated cultural knowledge from a variety of media sources regarding their topics (Jewitt, 2008; Kress, 2010).

\section{Student Engagement}

Data analysis from student observations and focus group interviews/group discussions showed that students were generally engaged in classroom. During the beginning of the course, the instructor informed the students that their group time was to be used as they wished: they could take breaks when they wanted and eat and drink if they wished. In other words, students were being treated as adults, and as such, they knew what they needed to accomplish, when their projects were due, and were responsible for their own work, and therefore, the grades they were to ultimately receive. This approach to student group projects is consistent with $\mathrm{CP}$ approaches to education and is theorized to increase 
student engagement, autonomy, and critical thinking skills (Beach \& Meyers, 2001; Kincheloe, 2004). As each student group chose to find separate rooms to work in and the instructor had to circulate among the groups, the observational data on student engagement is somewhat imprecise. The reason for this is that because of the autonomy that was given them, sometimes the students were not present when the instructor visited them. In addition, it sometimes occurred that students were outside or in other rooms recording student-acted video segments for their projects. It also needs to be stated that when groups were observed to be deeply engaged in their work, the researcher chose to leave them alone and merely check on them twice during the course period. However, it also became clear that some groups also worked on their projects on their own time as well, particularly in the week before the project was due.

Student-instructor discussions clearly showed that students were not only actively engaged in their work, but were also thinking critically about their topic, how it was to be represented through their video representation, and that some actually enjoyed what they were doing. When asked about how they felt about the course Sangmi, speaking for her group, replied that "We like this course because we can say our opinions freely with nobody correcting us. You just push us to think about them more" (December 8, 2016). Byungwoo expressed a different reason for his motivation for his work by relating that "We get to think about something that's important to us and be creative in how we show what it means to us" (November 28, 2016). In general, all student groups appeared to on task and student-researcher discussions were always lively. However, it must also be stated that not all groups were at the same level of engagement. One group always managed to engage in discussions and complete their project but was also seen to be obviously bored and idle at times. Nonetheless, the other two groups displayed high levels of engagement throughout the course. These results were particularly apparent in the quality of the video representations they produced. Thus, given the data at hand, and considering the time students were left to their own devices, the quality of their work attests that most students were highly engaged in their work, which supports the literature on student engagement in $\mathrm{CoP}$ and inquiry education group projects (Barton \& Hamilton, 1999; Beach \& Meyers, 2001; Crafton \& Kaiser, 2011).

\section{Student Topic Selection}

Of the nine-student group multimodal video representation projects only two concerned issues that were of an international nature, although others also contained some multimodal elements extant from Korean culture. The student focus on issues important to Korean society is not surprising as students were encouraged to choose topics from issues that were important to Korean and/or international society and were of personal 
interest to them. For the digital storytelling project, student groups could not tell individual, personal stories because of the nature of group work. Therefore, groups chose to tell the stories of famous people from Korean society or what it is like to be a Korean person in a specific social situation. As such, the three student groups chose to represent the life of the Korean national hero Admiral Yi Sun Sin of the Joseon dynasty, the speed skater Victor Ahn who left Korea for Russia because of corruption in the national sporting agency, and a day in the life of a Korean public high school student. All of these projects were specifically Korean in cultural content apart from the use of English text and narration in the video representation, thus showing little target cultural inquiry apart from the topics representation in English.

The issues chosen for the multimodal video representation projects were also more focused on Korean culture than being international in nature. Examples of specifically Korean issues used for student projects were video representations on No Kids Zones, what it means to be a Korean public-school student, the horror of Korean puppy farms, and juvenile smoking problems in Korea. While it is reasonable to assume that student groups would choose topics currently under debate in Korean society, what is surprising is that all of the videos made multimodal connections to other cultures in their final video representations. For example, the group video representing the Korean social phenomenon of restaurants and other commercial enterprises enacting "No Kids Zones", which focused on the issue of bad parenting, showed a video clip of Chinese mothers watching their small boys damage a museum artifact while taking a video of them on their smart phones. Another example was a clip of an obviously tired Korean high school student trying to study while the narration of the student's thoughts wonders; "What would it be like to be an American student and be able to sleep well and have some fun with friends?". Thus, while student groups tended to choose topics of specific interest within Korean society, students were able to situate these issues into a wider cultural frame. The group videos that were of more international interest were those of Judging by Appearance and Gender Equality. While both of these group multimodal video representations chose to use a variety of multimodal elements from a variety of cultures, they still contoured the meanings they were making to explicate how these issues were represented in Korean society and how they affected both individuals and the society. Examples of this are the use of a film clip from Kings Men (Bohling \& Vaughn, 2014) where the King's man defeats a group of young gangsters in a pub to show that appearances can be deceiving and the digital photos used of Western 'Supermodels' and expensive cosmetics in the video representation on Gender Equality. Thus, students not only showed that project-based pedagogies foster student engagement and creativity (Goldman, 2007; Jewitt, 2008; Kress, 2010), they also foster a better understanding of their topics through inquiry (Beach \& Myers, 2001; Crafton \& Kaiser, 2011). 


\section{Critical Thinking}

The data from the code of critical thinking showed that a CP approach to the course facilitated student development of critical thinking skills over the term of the semester. However, due to the nature of the pedagogy employed, it was not possible to discern the levels of critical thinking in all of the students for two reasons. First, while there was a marked reduction in language fear, some students remained somewhat reticent in speaking around the instructor (Ellis, 1994; MacIntyre \& Gardner, 1991). Second, the groups organized themselves around roles that are common in studies on group dynamics so that one student took a leading role as a spokesperson for the group, while other group members fulfilled other roles (Chang, 2010). Thus, it was at times difficult for the instructor to discern the levels to which students were developing their critical thinking skills. However, all students did participate, to greater or lesser degrees, in studentinstructor discussions and observational data showed that students were actively engaged in discussion in Korean while they were left alone, excepting one three student group that often appeared to be off task. Examples of the development of critical thinking skills may be best seen in the student group whose social issue was that of gender inequality. Initially, the students were focused on male dominance and how Korean women were forced into traditional female roles and did not have equal opportunities for employment and salaries as did Korean men. However, instructor questioning often spurred students to think more deeply on their topic as follows:

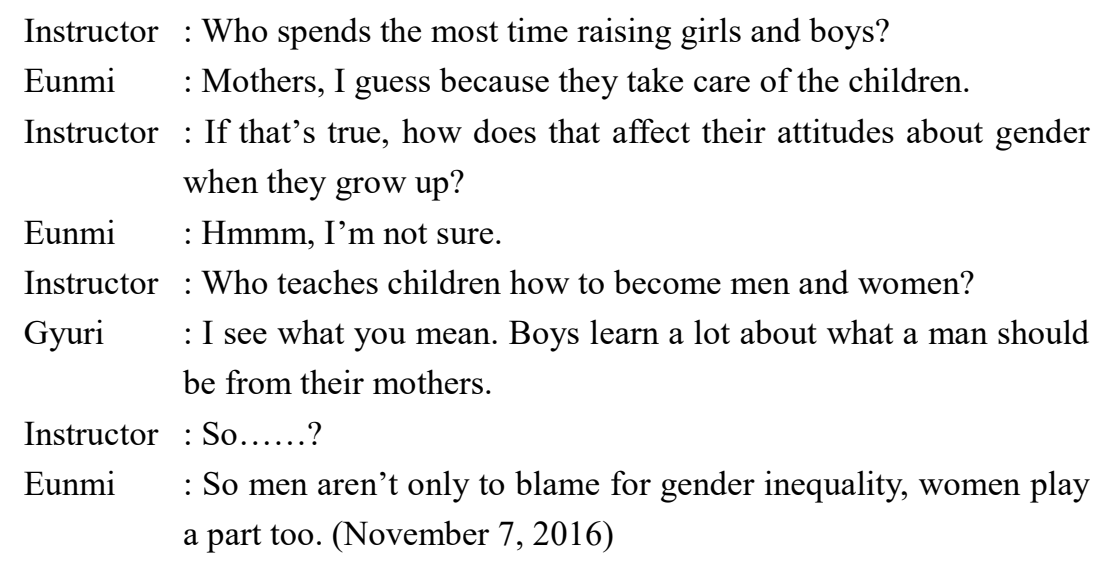

This discussion is indicative of how the researcher encouraged students through teacher questioning to think more deeply on the history and relations of power concerning the issue under inquiry (Beach \& Myers, 2001). This quote is striking in that it reflects current feminist theory in that women are somewhat complicit in their own domination (Bordo, 
2003).

During a later discussion, the group made a similar intellectual breakthrough regarding the effects of media representations on women while discussing the high percentage of young women receiving cosmetic surgery in Korea.

Instructor : Why is the rate of cosmetic surgery so high in Korea?

Yumi : Well, getting a good job is very competitive in Korea and looking good is important.

Instructor : Is that the only thing women do to be competitive?

Nari : If they can afford it, they buy expensive clothes and cosmetics.

Instructor : Does this have anything to do with how Korean women are represented in media?

Nari : I guess it would have to, wouldn't it?

Eunmi : With women being portrayed in media as so beautiful, happy, and fashionable, it makes real women feel bad because they can't look like that. So, they spend a lot of money on cosmetic surgery, clothing, and cosmetics.

Instructor : So who benefits from this?

Yumi : Big companies owned by men who sell beauty products and the media who advertises them. (November 23, 2016)

The same group's later video on the life of Korean public-school students made connections between the stress brought on by high-stakes testing, the concomitant competition for grades, and lack of sleep and play. Nonetheless, their video representation also included how these factors may cause a lack of family connection, creativity, and intellectual development, and a willingness to be passive workers. Similar connections were made by a group of male students on juvenile smoking that related how smoking was linked to representations of 'being cool' in movies and globalization in terms of 'being modern'. Thus, as is indicative of the development of critical thinking skills (Kincheloe, 2004), the data showed an increase in student willingness and ability to look deeper into the causes and social consequences of the issues they were representing over the term of the semester.

Finally, data from student group multimodal video representations demonstrated that not only was there a great deal of thought and planning committed to the construction of the video representations, but that they also showed a depth of thinking that was critical in nature. Observational and group discussion data showed that all student groups were involved in inquiry projects that not only necessitated discussion and critical thinking, but research as well. The student group video representation on the life of a Korean public- 
school student illustrates these two qualities in $<$ Figure $1>$.

\section{FIGURE 1}

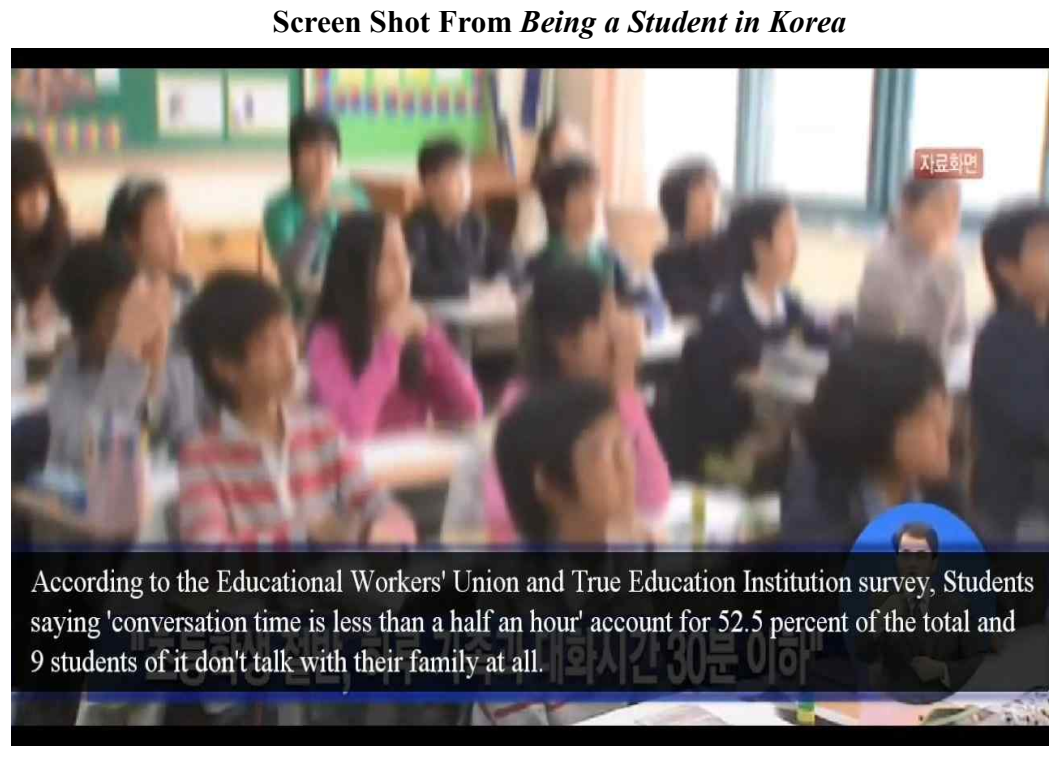

Here, the video clip clearly shows not only the online research that was done by the group, but also their awareness of the individual consequences for students and the larger implications for Korean society. Similarly, <Figure $2>$ illustrates how the group representation on Gender Equality understood the consequences of how multimodal video representations affect women.

FIGURE 2

Screen Shot From Gender Equality

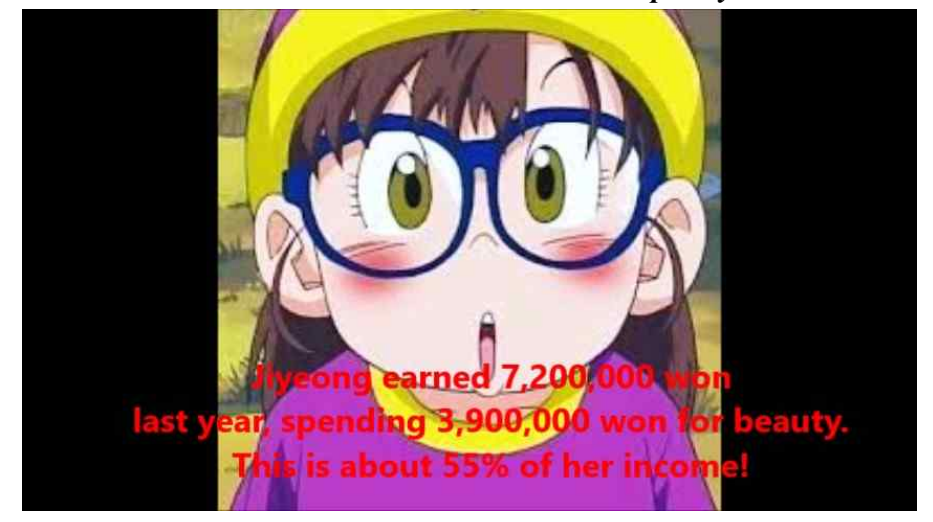


Finally, $<$ Figure $3>$ shows how the group video representation of Judging by Appearance makes its summation of the pressures to be fashionable and what is best for both the individual and society.

FIGURE 3

Screen Shot From Judging by Appearance

\section{Therefore, you should think critically with a distance from apperance. This is why you need to Judge by critical thinking not by appearance.}

Data analysis of student group multimodal video representations shows that most students were not only highly engaged in the construction of their projects, but were also involved in discussions, inquiry activities, and critical thinking. Thus, this study tends to confirm current research on inquiry education/multimodal projects in terms of their capacity to enhance levels of student engagement (Butler-Pascoe \& Wiburg, 2003; Liversidge, 2000), knowledge of the issue under inquiry (Jewitt, 2008; Kress, 2010), and facilitate the development of students' critical thinking skills (Chapple \& Curtis, 2000; Wang, 2015).

\section{DISCUSSION}

The results of this study suggest that $\mathrm{CP}$ approaches to the construction of student group multimodal video representations in a Korean university English Education classroom may be effectively employed. Regarding the research question of the types of topics students selected for their projects and why, the data showed that students tended to choose topics that were connected to their own lives as individuals and members of Korean society. However, even the two projects that were more international in nature (Judging by Appearances and Gender Equality) displayed representations that were both international and Korean in nature. This finding is in keeping with CP approaches in that a key aspect 
in the overall pedagogical approach is on of situating knowledge within individual and larger social contexts (Barton \& Hamilton, 1999; Kincheloe, 2004). Moreover, as the primary purposes of $\mathrm{CP}$ are those of transformative practices for more socially just societies and the development of social agency (Giroux, 1997; Kincheloe, 2004), it is natural that students should be primarily concerned with the social practices of their own societies (Kincheloe, 2004). In addition, the development of theories of situated learning theorize that in order to gain a more informed understanding of a specific social issue or form of knowledge, it is necessary to situate it within multiple contexts (Barton \& Hamilton, 1999; Pederson, 2012). Thus, in varying degrees each student group multimodal video representation focused on important Korean social issues, while also managing to connect them to larger international contexts.

The primary affect the CP approach employed in this study had on language learning was the general reduction of language fear. The results showed that all students gained some measure of confidence in using English both in their groups and with their instructor. Language fear is a well-documented phenomenon in ELT literature that includes disparate causes for student fear, or reluctance, to speak the target language. Among the many reasons for this reluctance is the fear of making grammatical errors and a greater reluctance to speak to native speaking instructors (Ellis, 1994; MacIntyre \& Gardner, 1991). The fear of making grammatical errors while speaking is generally attributed to the effects of highstakes testing and the competition for grades that it creates in the language classroom (Shin, 2010). Thus, the student may not only show reluctance to make errors in front of the teacher but may also be reluctant to look bad to her peers. However, the data from this study clearly showed that students gained speaking confidence over the period of the semester. This data shows that the CP approach to pedagogy employed, where the instructor regularly joined student group discussions, gradually reduced students' fear of speaking the target language with the instructor and each other. While some students remained relatively quiet during these discussions, they nonetheless did speak when they had an important point to make. Moreover, the majority of students in the class exhibited a gradually increasing confidence in speaking about their ideas, opinions, and plans over the semester. The data also suggests that this increasing confidence is also related to the nature of the discussions in that the instructor not only openly listened to and discussed the issues at hand in the group, he also suggested that students consider other possible interpretations and points of inquiry to the students. Thus, as the instructor was a de-facto member of each group, an open-ended conversation over content, opinions, and the implications of the work occurred over the duration of each project period. As such, the relaxed atmosphere of the group discussions decreased student reticence which resulted in increasing student engagement in group discussions over the semester (Barton \& Hamilton, 1999; Beach \& Meyers, 2001). 
The results of this study also showed that the CP approach utilized in the course facilitated student engagement in classroom activities. A common claim within CP literature is that student-centered, situated approaches to group projects more fruitfully engage students in classroom activities as they are more interested in the topics they choose which are connected to their lived experiences (Barton \& Hamilton, 1999; Beach \& Myers, 2001; Freire, 1998). In addition, the space created by CP in the classroom for dialogism and inquiry also enhanced student engagement as it allowed students to freely express their ideas without fear of ridicule or disapproval, which in turn facilitated the development of student voice (Giroux, 1997; Norton, 2000). As such, students were free to discuss, deconstruct, reconstruct, and represent knowledge in forms that were more informed and suitable for their society. Finally, the data showed that the space for a freedom of voice that $\mathrm{CP}$ created for students in the classroom was not only new to them, which also helps to explain their expressions of language fear, but also encouraged them to voice their own ideas and opinions. In essence, CP approaches are designed to create spaces where such freedom of expression and voice may occur, and that without such, $\mathrm{CP}$ would not be a viable pedagogical approach (Giroux, 1997; Kincheloe, 2004).

The results of this study show that the CP approach used to generate student group multimodal video representations facilitated the development of student's critical thinking skills. While it is clear that some students developed this skill to a greater degree than others, it is equally clear that all students developed some measure of this skill. It is worth noting that the traditional ELT methods of GTM and ALM generally employed in Korean K-12 English education, and the high-stakes testing regimes that support them, not only serve to stifle the development of critical thinking skills, but often retard the simple act of questioning the instructor. (Shin, 2010; Shin \& Crookes, 2005). The results of this study showed that while students were initially anxious about the nature of the pedagogy employed in the course, they nonetheless were increasingly enthusiastic and grateful for the opportunities to voice the opinions and ideas that a CP approach afforded them. Not only does CP literature theorize that the spaces created within the classroom for the situating and discussion of knowledge leads to student engagement, but that this engagement necessarily serves to enhance critical thinking skills (Freire, 1998; Kincheloe, 2004). Finally, the results show that through the guidance and suggestions of the instructor, students began making intuitive leaps of understanding in the social workings of power in terms of their effects on social justice and social agency, which is the ultimate goal of CP (Giroux, 1997: Kincheloe, 2004). In so doing, students were able to create insightful and thought-provoking multimodal video representations that demonstrated the processes of critical inquiry they successfully completed. 


\section{CONCLUSION}

This study investigated how the application of $\mathrm{CP}$ in the creation of student group multimodal video representations might facilitate language learning, student engagement in class activities, critical thinking skills, and help explicate what type of topics students preferred to choose. Through the use of digital storytelling and social issues group multimodal video representation projects, the results showed that CP created a space within the classroom that facilitated student engagement through the situating of knowledge within multiple contexts and discussing the implications of this inquiry with the instructor and their peers. This result agrees with the $\mathrm{CP}$ and multimodal literature that theorizes that such student projects as forms of situated pedagogies and the use of familiar multimodal technologies tend to enhance student engagement (Beach \& Myers, 2001; Butler-Pascoe \& Wiburg, 2003). While some students displayed some language fear during the early semester, they nonetheless managed to overcome much of this fear and speak more freely and openly as the semester progressed. Thus, the CP approach used in this study served to facilitate a reduction in students' language fear and an increased interest the target culture knowledge necessary in CLT and other social-constructivist approaches to second language learning (Savignon, 2002; Shin \& Crookes, 2005). In addition, in keeping with the nature of $\mathrm{CP}$ approaches, students tended to choose social issues that resonated with their own experiences and which expressed their interests (Barton \& Hamilton, 1999; Kincheloe, 2004; Kaiser, 2011). As such, while all but two of the video representations produced were specifically Korean in cultural terms, all videos did include other cultural aspects. Finally, as the CP approach used necessitated students to decode the meanings of popular media representations of the issues under inquiry and construct multimodal video representations showing their own meanings, students' critical thinking skills were developed (Beach \& Meyers, 2001; Crafton \& Kaiser, 2011). Thus, the use of CP not only encouraged second language use, it created a space where students were able to voice their opinions, ideas, and beliefs without fear of criticism or ridicule. Thus, through the development of critical thinking skills, students developed a better understanding of themselves and their society (Gee, 2010; Jewitt, 2008; Kincheloe, 2004; Kress, 2010). This research suggests that the use of CP approaches to multimodal group projects in ELT classrooms may be of great benefit to Korean English education at both the secondary and tertiary levels. While more research clearly needs to be undertaken, the body of research on these pedagogies and the familiarity of Korean youth with multimodal technologies suggests that $\mathrm{CP}$ approaches to multimodal projects in Korean English classrooms should be increasingly practiced. 


\section{REFERENCES}

Bahrani, T., \& Tam, S. (2011). Technology and language learning: Exposure to TV and radio news and speaking proficiency. Kritika Kultura, 17(2), 144-160.

Barbules, N. C., \& Berk, R. (1999). Critical thinking and critical pedagogy: Relations, differences, and limits. In T. S. Popkewitz \& L. Fendler (Eds.), Critical theories in education: Changing terrains of politics (pp. 45-65). New York, NY: Routledge.

Barton, D., \& Hamilton, M. (Eds.). (1999). Situated literacies. New York, NY: Routledge.

Beach, R. (2007). Teachingmedialiteracy.com: A web-linked guide to resources and activities. New York, NY: Teachers College Press.

Beach, R., \& Myers, J. (2001). Inquiry-based English instruction: Engaging students in life and literature. New York, NY: Teachers College Press.

Bohling, A., \& Vaughn, M. (Producers). (2014). Kingsman: The secret service [Motion picture]. United States: Twentieth Century Fox.

Bordo, S. (2003). Unbearable weight: Feminism, western culture, and the body. Sacramento, CA: University of California Press.

Butler-Pascoe, M., \& Wiburg, K. (2003). Technology and teaching language learners. Boston, MA: Pearson Education.

Canagarajah, S. (1999). Resisting linguistic imperialism in English teaching. Oxford: Oxford University Press.

Chang, L. (2010). Group processes and EFL learners' motivation: A study of group dynamics in EFL classrooms. TESOL Quarterly, 44(2), 129-154.

Chapple, L., \& Curtis, A. (2000). Content-based instruction in Hong Kong: Student responses to film. System, 28(3), 419-433.

Crafton, L., \& Kaiser, E. (2011). The language of collaboration: Dialogue and identity in teacher professional development. Improving Schools, 14(2), 104-116.

Creswell, J. (2003). Research design: Qualitative, quantitative, and mixed methods approaches. Thousand Oaks, CA: Sage.

Curtis, A. (2007). Film in the ESL classroom: Hearing the students voice. In H. McGarrell (Ed.), Language teacher research in the Americas (pp. 41-53). Alexandria, VA: TESOL Association.

Denzin, N., \& Lincoln, Y. (2011). Introduction to the design and practice of qualitative research. In N. Denzin \& Y. Lincoln (Eds.), The SAGE handbook of qualitative Research (pp. 1-21). Thousand Oaks, CA: Sage.

Dudeney, G. (2007). The Internet and the language classroom (2nd ed.). Cambridge, MA: Cambridge University Press.

Eken, A. (2003). You've got mail: A film workshop. ELT Journal, 57(1), 51-59. 
Ellis, R. (1994). The study of second language acquisition. Oxford: Oxford University Press.

Foucault, M. (1984). The Foucault reader. New York, NY: Random House.

Freire, P. (1970). Pedagogy of the oppressed. New York, NY: Continuum.

Freire, P. (1998). Pedagogy of freedom: Ethics, democracy, and civic courage. Lanham, MD: Rowman \& Littlefield.

Freyn, A. (2017). Effects of a multimodal approach on ESL/EFL university students' attitudes towards poetry. Journal of Education and Practice, 8(8), 80-83.

Gee, J. (2010). New digital media and learning as an emerging area and "Worked Examples" as one way forward. Boston, MA: MIT Press.

Giroux, H. (1997). Education and cultural studies: Toward a performative practice. New York, NY: Routledge.

Goldman, R. (2007). Video representations and the perspectivity framework: Epistemology, ethnography, evaluation, and ethnics. In R. Goldman, R. Pea, B. Barron, \& S. J. Derry (Eds.), Video research in the learning sciences (pp. 1-37). London: Lawrence Erlbaum Associates.

Guichon, N., \& McLornan, S. (2008). The effects of multimodality on L2 learners: Implications for CALL resource design. System, 36(1), 85-93.

Hall, S. (1997). Representation: cultural representations and signifying practices. Thousand Oaks, CA: Sage.

Hinkel, E. (1999). Culture in second language teaching and learning. Cambridge, MA: Cambridge University Press.

Hung, V., \& Yuen, A. (2014). Learning with video representation: A case study on the usage of multimodal elements for explaining community issues. Journal of Communication and Education, 1(1), 28-38.

Hymes, D. (1967). Why the linguist needs the sociologist. Social Research, 34(4), 632647.

Jewitt, C. (2008). Multimodality and literacy in school classrooms. Review of Research on Education, 32(1), 241-267.

Kaiser, M. (2011). New approaches to exploiting film in the foreign language classroom. L2 Journal, 3(2), 232-249.

Kellner, D., \& Share, J. (2007). Critical media literacy, democracy, and the reconstruction of education. In D. Macedo \& S. R. Steinberg (Eds.), Media literacy: A reader (pp. 3-23). New York, NY: Peter Lang.

Kincheloe, J. (2004). Critical pedagogy primer. New York, NY: Peter Lang.

King, J. (2002). Using DVD feature films in the EFL classroom. CALL, 15(5), 509-523.

Kramsch, C. (1993). Context and culture in language teaching. Oxford: Oxford University Press. 
Krashen, S. (1982). Principles and practice in second language acquisition. Hayward, CA: Alemany Press.

Kress, G. (2010). Multimodality: A social semiotics approach to contemporary communication. New York, NY: Routledge.

Kress, G., \& Van Leeuwen, T. (2006). Reading images: The grammar of visual design $\left(2^{\text {nd }}\right.$ ed.). New York, NY: Routledge.

Lamy, M., \& Hampel, R. (2007). Online communication in language learning and teaching. London: Palgrave Macmillan.

Lantolf, J. (2006). Sociocultural theory and second language learning: State of the art. Studies in Second Language Acquisition, 28(1), 67-109.

Lave, J., \& Wenger, E. (1991). Situated learning: Legitimate peripheral participation. New York, NY: Cambridge University Press.

Liversidge, G. (2000). Using films to develop learner motivation. Internet TESL Journal, 6(13). Retrieved from http://iteslj.org/Articles/Ryan-Films

Luke, A. (2011). Theory into practice. Retrieved from https://eprints.qut.edu.au/41519/ 2/41519.pdf

MacIntyre, P., \& Gardner, R. (1991). Methods and results in the study of anxiety and language learning: A review of the literature. Language Learning, 41(1), 85-117.

Meyers, J., \& Beach, R. (2004). Constructing critical literacy practices through technology tools and inquiry. Contemporary Issues in Technology and Teacher Education, 4(3), 257-268.

Miller, J., \& Kim, S. (2015). Digital storytelling as an integrated approach to second language learning and teaching. Language and Communication Quarterly, 4(1), 41-55.

Morgan, B. (2006). Poststructuralism and applied linguistics: Complementary approaches to identity and culture. In J. Cummins \& C. Davison (Eds.), International handbook of language teaching (Vol. 1, pp. 1033-1053). New York, NY: Springer.

Norton, B. (2000). Identity and language learning: Gender, ethnicity, and educational change. London: Longman/Pearson Education.

Pederson, R. (2012). Situated learning: Rethinking a ubiquitous theory. The Journal of AsiaTEFL, 9(2), 123-148.

Pennycook, A. (2001). Critical applied linguistics: A critical introduction. New York, NY: Routledge.

Royce, T. (2002). Multimodality in the TESOL classroom: Exploring visual-verbal synergy. TESOL Quarterly, 36(2), 191-205.

Savignon, S. (2002). Interpreting communicative language teaching: Contexts and concerns in teacher education. New Haven, CT: Yale University Press. 
Shin, H. (2010). Gireogi gajok: Transnationalism and language learning (Unpublished doctoral dissertation). University of Toronto, Toronto, Canada.

Shin, H., \& Crookes, G. (2005). Indigenous critical traditions for TEFL?: A historical and comparative perspective in the case of Korea. Critical Inquiry in Language Studies, 2(2), 95-112.

Sommer, P. (2001). Using film in the English classroom: Why and how. Journal of Adolescent and Adult Literacy, 44(5), 485-487.

Strauss, A., \& Corbin, J. (1998). Basics of qualitative research: Grounded theory procedures and technique. London: Sage.

Sung, K., \& Pederson, R. (2012). Critical practices in ELT as a project of possibilities or a banal discourse. In K. Sung \& R. Pederson (Eds.), Critical ELT practices in Asia (pp. 153-171). Amsterdam: Sense Publishers.

Terantino, J. (2011). Emerging technologies Youtube for foreign languages: You have to see this video. Language Learning \& Technology, 15(1), 10-16.

Vinogradova, P., Linville, H. A., \& Bickel, B. (2011). Listen to my story and you will know me: Digital stories as student-centered collaborative projects. TESOL Journal, 2(2), 173-202.

Vygotsky, L. (1978). Mind in society: The development of higher psychological processes. Boston, MA: Harvard University Press.

Wang, Q. (2015). Research into the new model of college English teaching: A multimodality approach. International Journal on Integrating Technology in Education, 4(3), 31-38.

Ward, J., \& Lepeintre, R. (1996). The creative connection in movies and TV: What Degrassi High teach teachers. The Journal of the Imagination in Language Leaning and Teaching, 3(2), 37-52.

Warschauer, M., \& Meskill, C. (2000). Technology and second language teaching and learning. In J. Rosenthal (Ed.), Handbook of undergraduate second language education (pp. 303-318). Mahwah, NJ: Lawrence Erlbaum. 
Critical Pedagogy as an Approach to Multimodal Video Projects

in Korean English Education Classrooms

Applicable levels: tertiary, secondary

Keywords: community of practice, multimodal, multiliteracies, video representation

\section{Pederson, Rod}

Department of English Education

Incheon National University

A-218 Michuhol Tower Annex

12 Gaelbeol-Ro, Songdo-Dong,

Yeonsu-Gu, Incheon, Korea 20199

E-mail: docrod88@hotmail.com

Received: March 29, 2018

Revised version: May 16, 2018

Accepted: May 26, 2018 